\title{
RUMAH ADAT USING BANYUWANGI: KAJIAN BUDAYA DALAM MEDIA PEMBELAJARAN MATEMATIKA
}

\author{
Rachmaniah M. Hariastuti \\ Pendidikan Matematika, FMIPA, Universitas PGRI Banyuwangi \\ Indonesia \\ mirzarachmania@gmail.com
}

\begin{abstract}
Abstrak
Rumah adat Using adalah suatu bangunan tradisional yang berfungsi sebagai tempat tinggal yang dibangun oleh masyarakat suku Using, Banyuwangi. Sebagai bagian dari budaya, rumah adat Using memiliki banyak hal yang dapat dieksplorasi untuk dapat diketahui bentuk dan struktur dasarnya. Rumah adat Using merupakan bagian dari pola hidup serta adat istiadat dari suatu masyarakat di suatu daerah yang disadari atau tidak memuat konsep-konsep matematika namun tidak disadari secara langsung oleh masyarakat. Hasil eksplorasi terhadap bentuk dan struktur rumah adat Using menunjukkan bahwa terdapat konsep pembelajaran matematika sederhana khususnya geometri. Hal ini menjadi dasar pengembangan media pembelajaran matematika berbasis rumah adat Using.
\end{abstract}

Kata kunci: Rumah Adat Using, Media Pembelajaran Matematika, Geometri

\section{Abstract}

Using traditional house is a traditional building that functions as a residence built by Using tribe people, Banyuwangi. As part of culture, Using custom houses have many things that can be explored to find out their basic shape and structure. Using traditional house is part of the pattern of life and customs of a society in an area that is realized or does not contain mathematical concepts but is not realized directly by the community. The results of exploration of the shape and structure of Using traditional houses show that there are concepts of simple mathematics learning, especially geometry. This has become the basis for the development of using traditional home based mathematics learning media.

Keywords: Traditional Using House, Learning Media Mathematics, Geometry

\section{Pendahuluan}

Bangsa Indonesia merupakan bangsa yang kaya akan keragaman budaya. Salah satu keragaman budaya tersebut tampak pada rumah adat tiap suku pada berbagai daerah. Rumah adat merupakan suatu bangunan yang memiliki ciri khusus dan digunakan untuk tempat tinggal suku tertentu. Seiring perkembangan zaman dan teknologi, penggunaan rumah adat sebagai tempat tinggal sudah mulai ditinggalkan. Namun hal ini tidak berarti bahwa masyarakat harus melupakan tentang potensi rumah adat sebagai bagian dari budaya.
Rumah adat dapat menjadi representasi budaya yang paling tinggi dalam sebuah komunitas masyarakat. Kabupaten Banyuwangi merupakan salah satu Kabupaten dengan representasi budaya yang beragam. Posisi kabupaten yang berbatasan dengan Kabupaten Jember dan Bondowoso di sebelah barat, Kabupaten Situbondo dan Bondowoso di sebelah utara, Selat Bali di sebelah timur dan Samudra Indonesia di sebelah selatan memungkinkan berkembangnya berbagai budaya pada masyarakat Banyuwangi.

Posisi Banyuwangi tersebut memungkinkan berkembangnya budaya 
pada masyarakat Banyuwangi. Keberadaan suku asli Banyuwangi yang bernama suku Using (pada beberapa referensi lain disebut Osing), menunjukkan bahwa Banyuwangi memiliki perkembangan kebudayaan yang sangat baik. Berbagai hal terkait budaya suku Using telah banyak menjadi pengkajian baik dari segi budaya maupun hal-hal lain, salah satunya tentang rumah adat suku Using.

Rumah adat suku Using masih dipertahankan di beberapa daerah di
Banyuwangi. Beberapa desa yang masih memperlihatkan kekhasan budaya Osing, bahkan disebut pusat komunitas Osing adalah Desa Kemiren, Kecamatan Glagah dan Desa Aliyan, Kecamatan Rogojampi (Suprijanto, 2002:13). Menurut Yuliatik \& Puji (2014:23) rumah Using memiliki tampilan ruang yang sederhana dan identik dengan rumah kampung. Hal ini berkaitan erat dengan struktur sosial pada masyarakat Using yang mewakili lapisan masyarakat biasa.

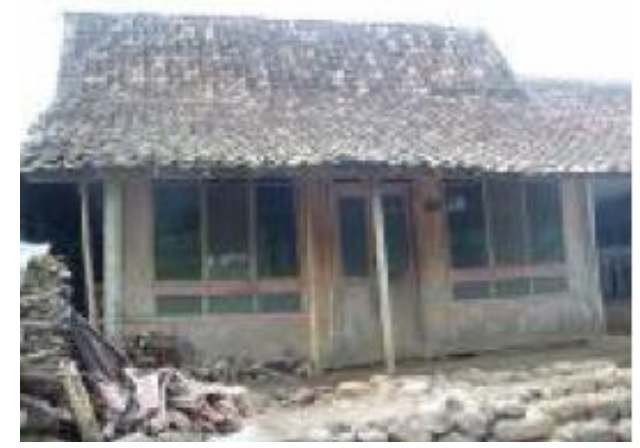

Gambar 1. Rumah Adat Using, Banyuwangi (Setyabudi, 2011:4)

Keberadaan rumah adat suku Using yang masih dipertahankan, bahkan dilestarikan dan dikembangkan kembali di beberapa kawasan, menjadikan rumah adat Using bahan yang menarik untuk dikaji secara budaya dan pembelajaran berbasis etnografi. Salah satu pembelajaran yang dapat dikembangkan dengan dasar rumah adat Using adalah matematika. Hal ini dapat dilakukan karena secara nyata atau tersirat dapat ditemukan konsep-konsep matematika dalam budaya masyarakat, khususnya rumah adat Using.

Konsep-konsep matematika yang diterapkan dalam suatu budaya masyarakat dikenal sebagai etnomatematika. Zhang \& Zhang (2010:151) berpendapat "ethnomathematics is often defined as the research on the relationship between mathematics (mathematics education) and the corresponding social and cultural backgrounds, namely the research shows how is matyematics produced, transferred,

\section{METODE}

Penelitian ini merupakan penelitian eksploratif-deskriptif yang bertujuan untuk mengeksplorasi bentuk dan struktur rumah diffused and specialized in diverse cultural systems", yang dapat diterjemahkan sebagai: etnomatematika sering diartikan sebagai studi tentang hubungan antara matematika (pembelajaran matematika) dengan latar belakang sosial budaya yang berhubungan yang menunjukkan bagaimana matematika dihasilkan, dialihkan, disebarkan dan dikhususkan dalam sistem budaya yang beragam. Pendapat tersebut menunjukkan bahwa dalam setiap kegiatan sosial budaya memuat konsep-konsep matematika yang secara khusus dapat dikembangkan dalam proses pembelajaran.

Berdasarkan pembahasan di atas dapat ditentukan rumusan masalah sebagai berikut: (1) bagaimana bentuk dan struktur rumah adat suku Using ?; (2) Bagaimana pengembangan media pembelajaran berbasis etnomatematika rumah adat suku Using?.

adat suku Using, kemudian mengembangkan media pembelajaran matematika berbasis bentuk dan struktur rumah adat suku Using. Daerah penelitian ditentukan di Desa Kemiren, Kecamatan 
Glagah, Kabupaten Banyuwangi yang dipilih karena populasi rumah adat Using di daerah tersebut masih cukup banyak.
Penelitian dilakukan berdasarkan kerangka sebagai berikut:

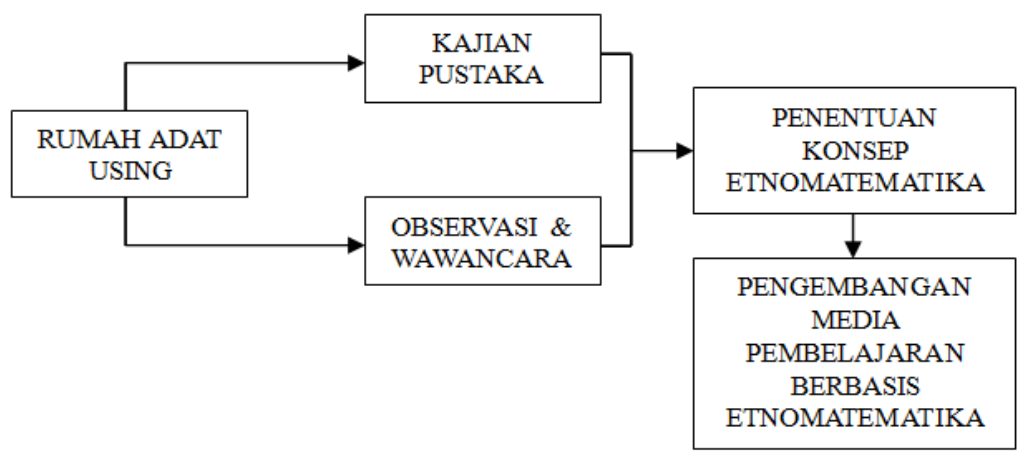

Gambar 2. Kerangka Penelitian

Data diperoleh melalui kajian pustaka, observasi, dan wawancara dengan narasumber yang ditentukan secara Purposive Sampling. Narasumber merupakan pemilik rumah adat suku Using di Desa Kemiren dan seniman Using Banyuwangi. Hasil kajian pustaka dan observasi serta wawancara dengan narasumber digunakan sebagai bahan penentuan konsep etnomatematika pada rumah adat Using.

Penelitian difokuskan pada eksplorasi bentuk dan struktur rumah adat Using kemudian mengembangkan media pembelajaran matematika berbasis bentuk dasar rumah adat Using tersebut. Pengembangan media pembelajaran dilakukan dengan model ADDIE (Analysis, Design, Development, Implementation, and Evaluation) yang dibatasi sampai pada development. Hal ini dilakukan karena keterbatasan waktu sehingga tidak dilakukan validasi, ujicoba, dan evaluasi produk. Hasil pengembangan media dianalisis berdasarkan indikator konsep pembelajaran matematika yang bersesuaian.

\section{HASIL DAN PEMBAHASAN}

Rumah adat merupakan suatu bangunan berciri tradisional yang difungsikan sebagai tempat tinggal dan aktivitas yang lain oleh sekumpulan masyarakat suku tertentu. Akibatnya rumah adat tiap-tiap suku di Indonesia pasti memiliki ciri tententu yang membedakan antara satu suku dengan suku lainnya. Rumah adat Using adalah bangunan tempat tinggal yang dibuat oleh suku Using di Banyuwangi.

Salah satu daerah yang masih banyak melestarikan rumah adat Using adalah wilayah Desa Kemiren, Kecamatan Glagah, Kabupaten Banyuwangi. Desa Kemiren juga dikenal sebagai Desa Adat oleh masyarakat suku Using. Berbagai budaya diupayakan untuk terus dilestarikan di Desa Kemiren, salah satunya rumah adat suku Using. 

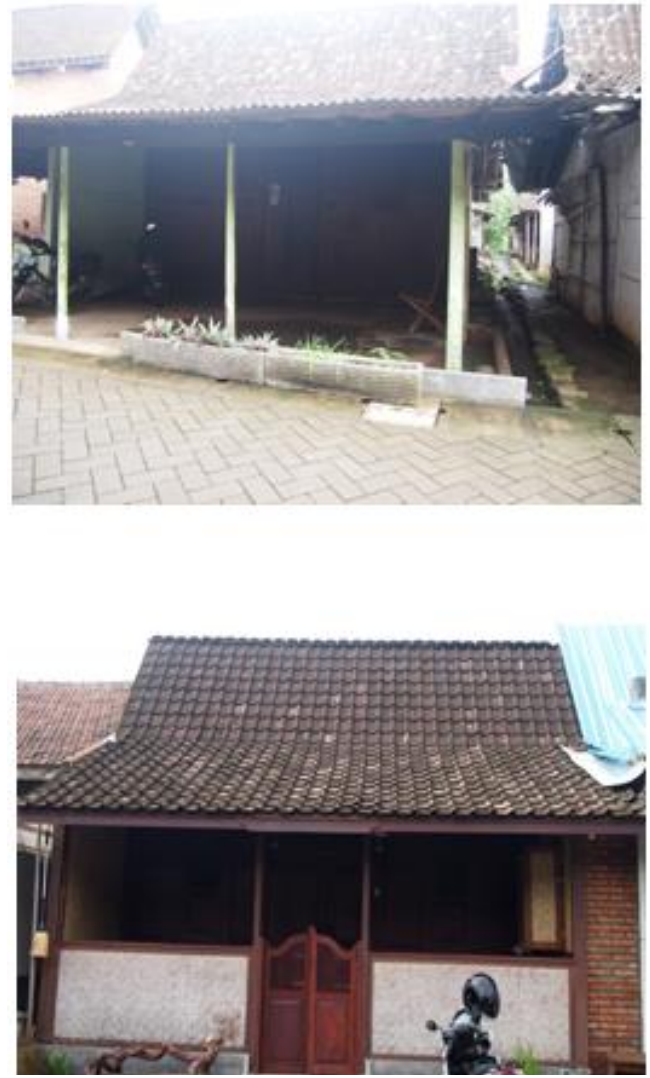

Gambar 3. Beberapa Rumah Adat Using di Kawasan Desa Wisata Kemiren

Menurut Senjaya \& Gunawan (2014:343) rumah tradisional Osing memiliki keunikan dari segi bentuk arsitektural dan struktur konstruksinya yang berbeda dengan rumah adat tradisional di daerah lain. Keunikan tersebut dapat menjadi bahan untuk mengenalkan pada masyarakat mengenai identitas asli rumah Using. Rumah adat Using berorientasi kosmologis utara-selatan (Nur, dkk,
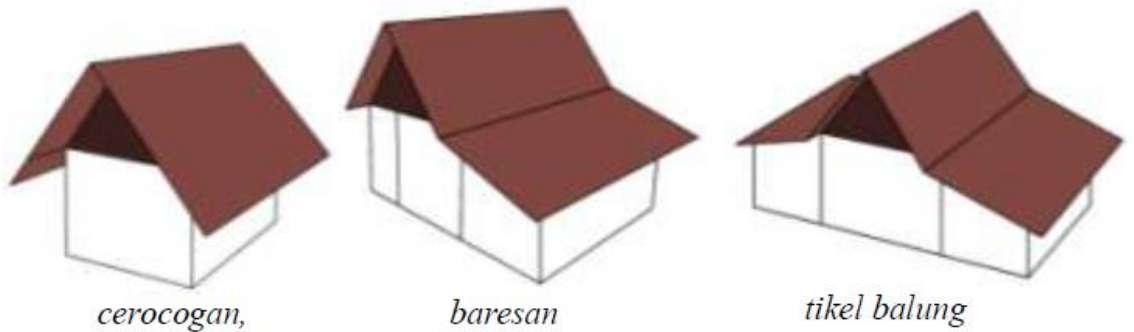

tikel balung

Gambar 4. Bentuk Atap Rumah Adat Using (Nur, dkk, 2010:66)

Menurut Setyabudi (2011:6) atap terbagi menjadi tiga bentukan, yaitu (1) cerocogan yang hampir sama dengan rumah kampung pada umumnya (terdiri atas dua sisi atap/pelana); (2) baresan terdiri atas tiga sisi yang biasanya terdapat pada desa

DOI: $10.31227 /$ osf.io

tradisional seperti di Baran, Malang; dan (3) tikel balung yang terdiri atas empat sisi. Menurut narasumber hingga saat ini yang masih banyak digunakan oleh masyarakat adalah bentuk tikel dan cerocogan yang luasnya menyesuaikan dengan luas tanah 
Pendidikan Budaya dan Sejarah "Dibalik Revitalisasi Budaya"

ISBN: 978-602-72362-7-1

yang digunakan.

Ruangan menjadi bagian yang penting dalam rumah adat Using. Tiap ruangan memiliki fungsi tertentu sesuai kebutuhan masing-masing keluarga. Secara umum rumah adat Using dibagi menjadi tiga ruangan yaitu mbyale, jerumah, dan pawon. Mbyale merupakan ruangan tempat menerima tamu atau berkumpulnya keluarga. Jerumah adalah bagian pribadi dari pemilik rumah yang dapat diasumsikan juga sebagai kamar tidur. Sedangkan pawon adalah dapur.
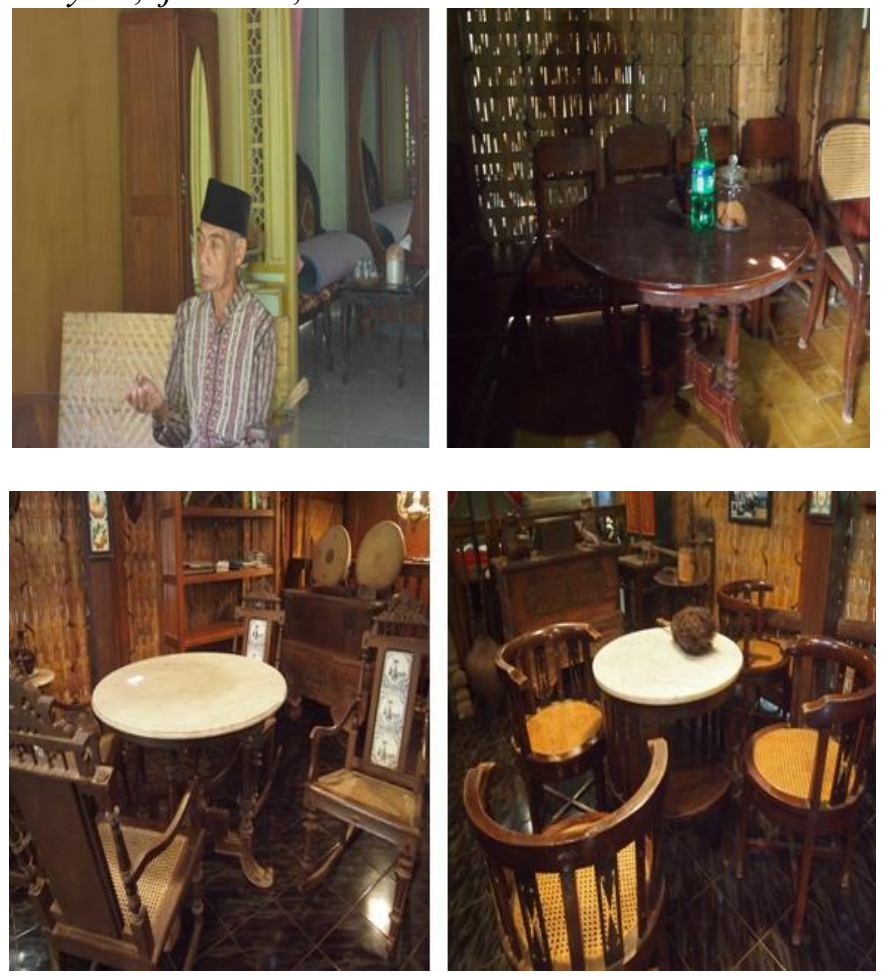

Gambar 5. Mbyale pada Rumah Adat Using
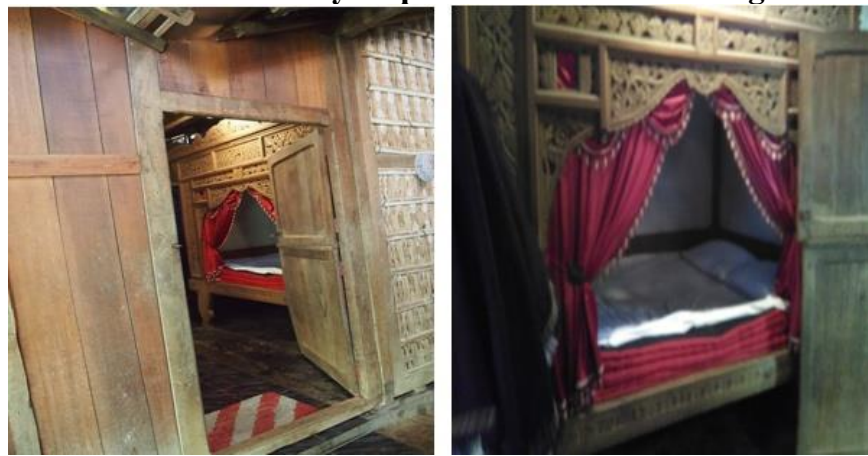
FKIP Universitas PGRI Banyuwangi Seminar Nasional

Pendidikan Budaya dan Sejarah: "Dibalik Revitalisasi Budaya"

ISBN: 978-602-72362-7-1
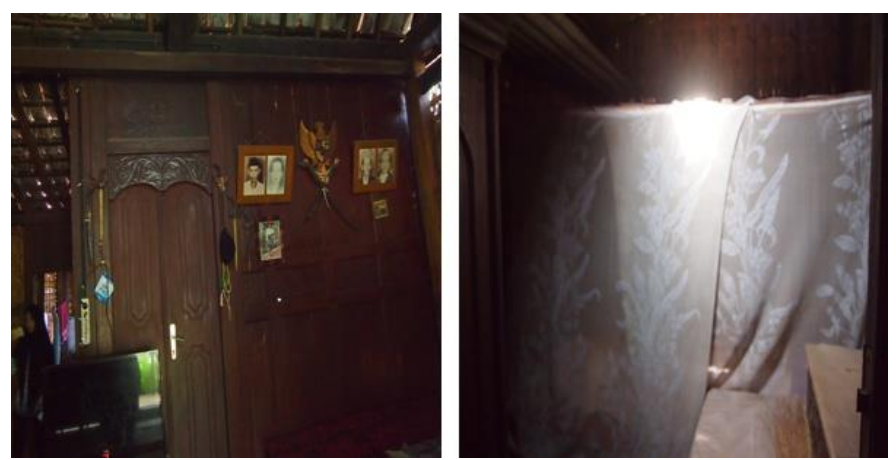

Gambar 6. Jerumah pada Rumah Adat Using
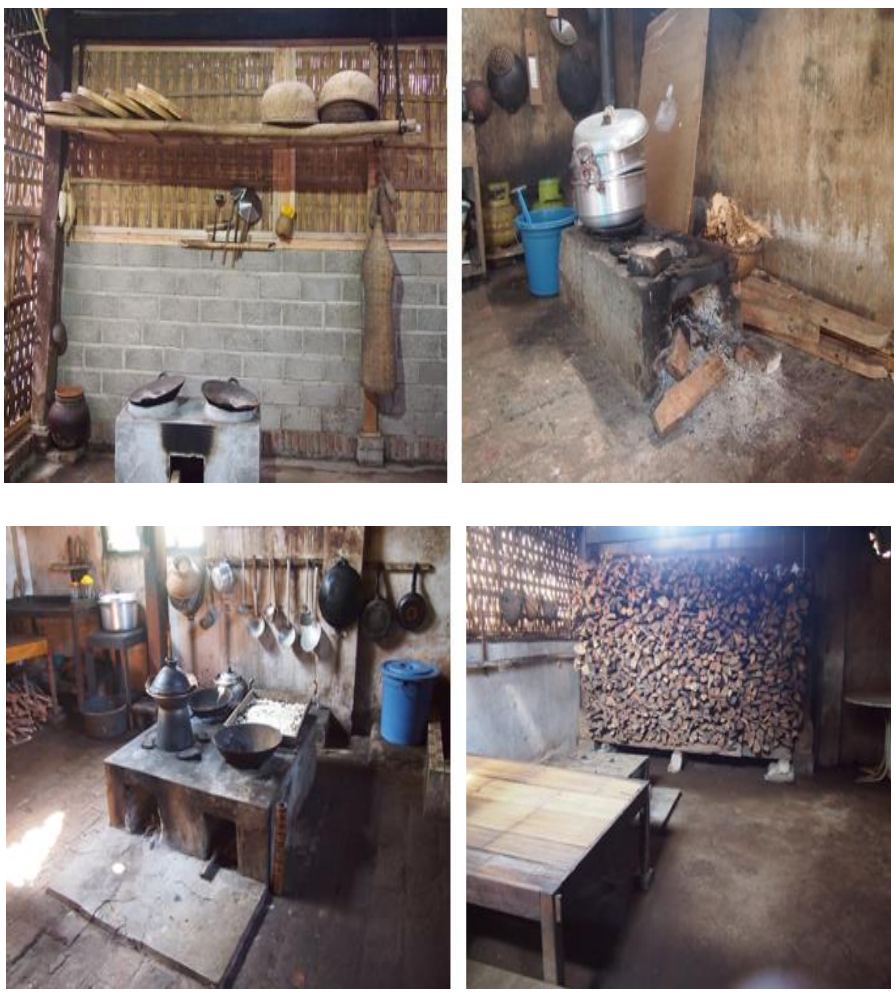

Gambar 7. Pawon pada Rumah Adat Using

Menurut Suprijanto (2002:16) struktur utama rumah Using berupa susunan rangka 4 tiang (saka) kayu dengan sistem tanding tanpa paku, tetapi menggunakan paju (pasak pipih). 


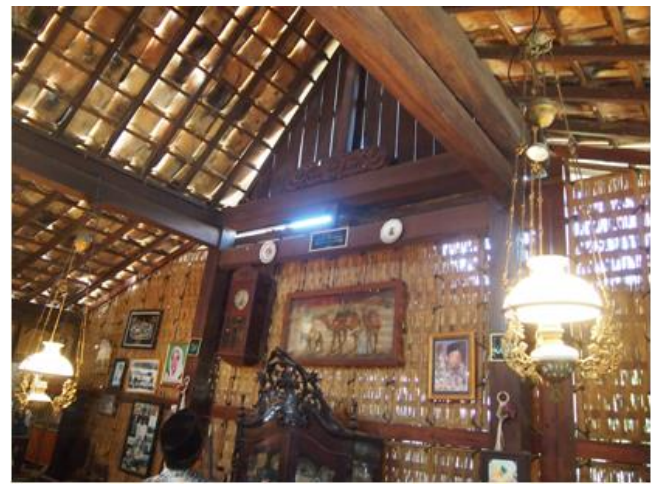

Gambar 8. Komponen Kayu dalam Rumah Adat Using

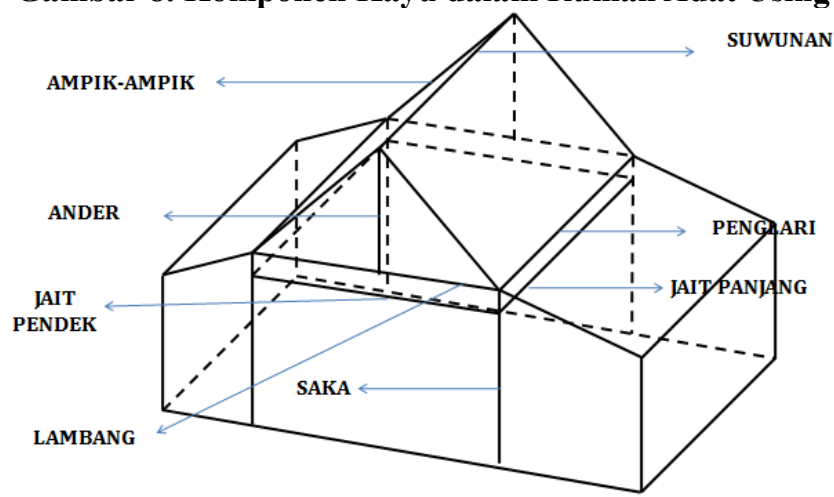

Gambar 9. Komponen Kayu dalam Kerangka Rumah Adat Using

Berdasarkan hasil wawancara dengan narasumber diperoleh keterangan tentang komponen-komponen kayu dalam rumah adat Using. Kayu panjang di atas rumah disebut dengan suwunan. Dua kayu yang berdiri pendek dinamakan ander. Kayu yang membentu sisi-sisi miring segitiga disebut ampik-ampik. Kayu dibawah ander dinamakan lambang dan dibawah lambang terdapat jait pendek yaitu tiang yang menghubungkan saka depan ke saka belakang. Kayu yang menghubungkan dua lambang disebut penglari dan dibawah penglari terdapat jait panjang yaitu tiang yang menghubungkan saka kiri dan saka kanan (Hasil wawancara dengan narasumber).

Dinding rumah umumnya masih terbuat dari anyaman bambu (gedheg). Gedheg tersebut umumnya digunakan sebagai dinding samping dan belakang serta partisi rumah (Suprijanto, 2002:16). Menurut narasumber, anyaman bambu pada dinding rumah adat Using hanya berfungsi sebagai penutup dan motifnya terserah pada pemilik rumah. Pada ruang selain kamar tidur (jerumah) digunakan anyaman bambu tunggal sehingga sirkulasi udara tetap segar. Sedangkan pada bagian jerumah digunakan anyaman bambu yang ganda agar tidak terlihat bagian dalam ruangan dari luar. 

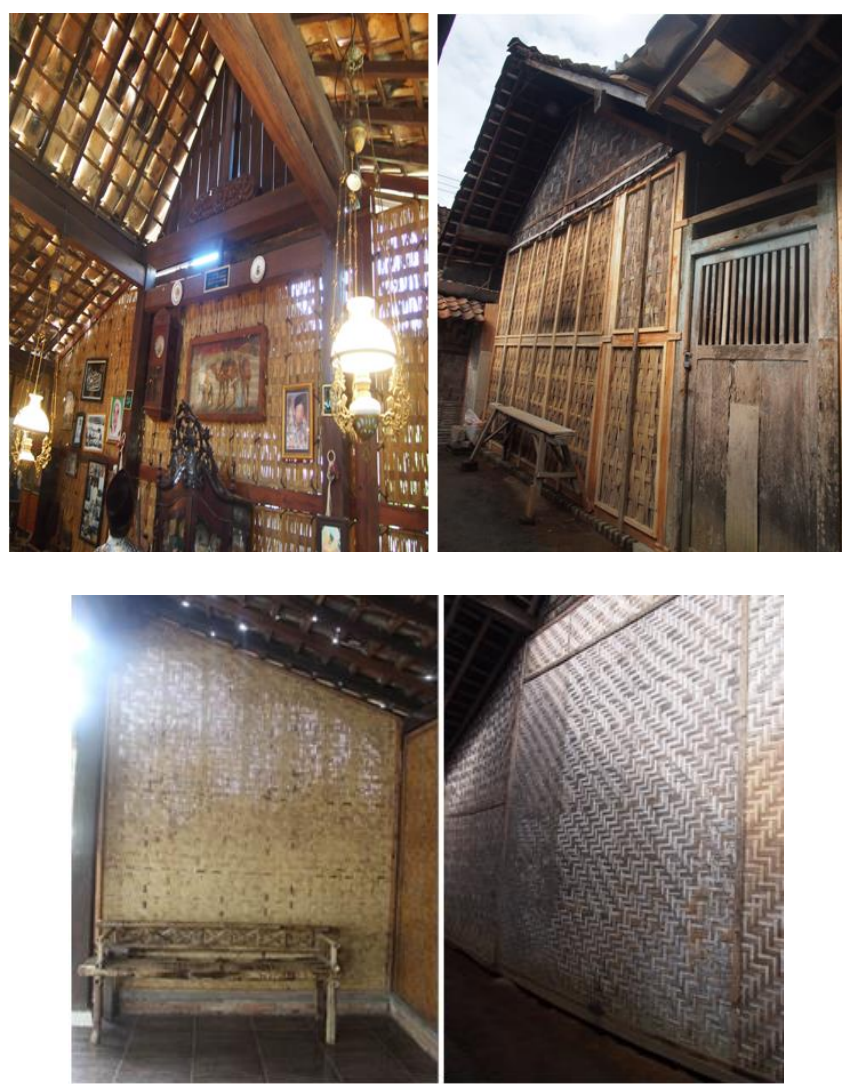

Gambar 10. Dinding Gedheg pada Rumah Adat Using

Berdasarkan bentuk dan struktur dasar rumah adat Using yang telah dieksplorasi, dapat dilakukan pengembangan media pembelajaran matematika berbasis rumah adat Using tersebut. Media pembelajaran matematika
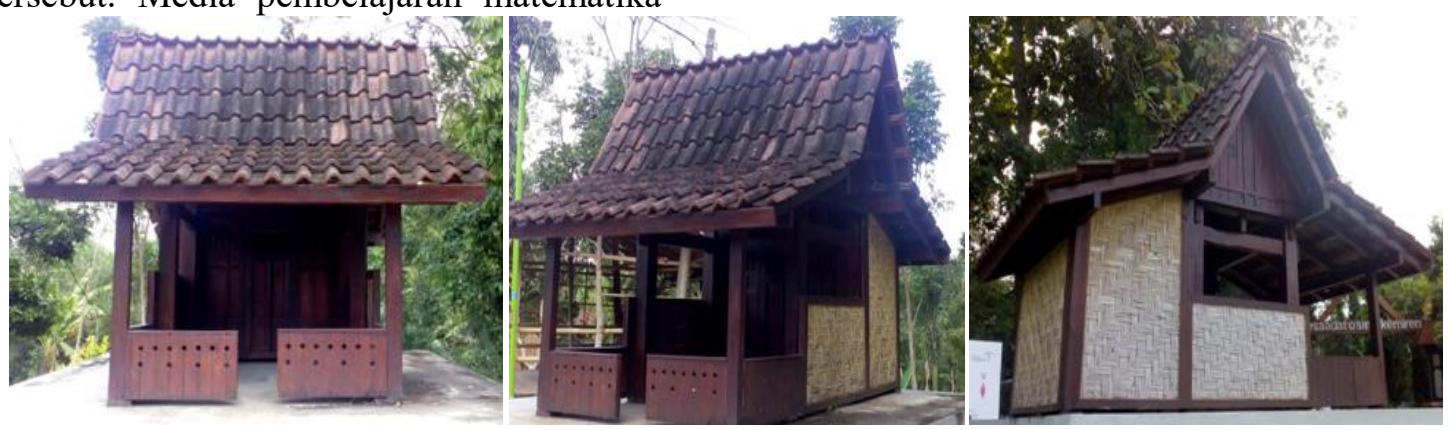

Gambar 11. Miniatur Rumah Adat Using di Desa Kemiren

Miniatur rumah adat Using yang ada di Desa Kemiren memberikan inspirasi bahwa bentuk dasar rumah adat Using dapat digunakan sebagai media pembelajaran untuk mengenalkan konsepkonsep dasar bidang datar sederhana khususnya bangun segiempat dan segitiga. ini dikhususkan pada pembahasan materi geometri. Selain untuk pengenalan bentuk bidang datar sederhana, media ini juga dapat digunakan untuk pengenalan konsep kesebangunan dan kekongruenan.
Selain itu adanya perulangan bentuk yang serupa seperti pada genting, dinding, pagar, dan lain-lain juga dapat digunakan sebagai media untuk mengenalkan konsep kesebangunan dan kekongruenan.

Pengembangan media tersebut dilakukan dalam bentuk berikut. 


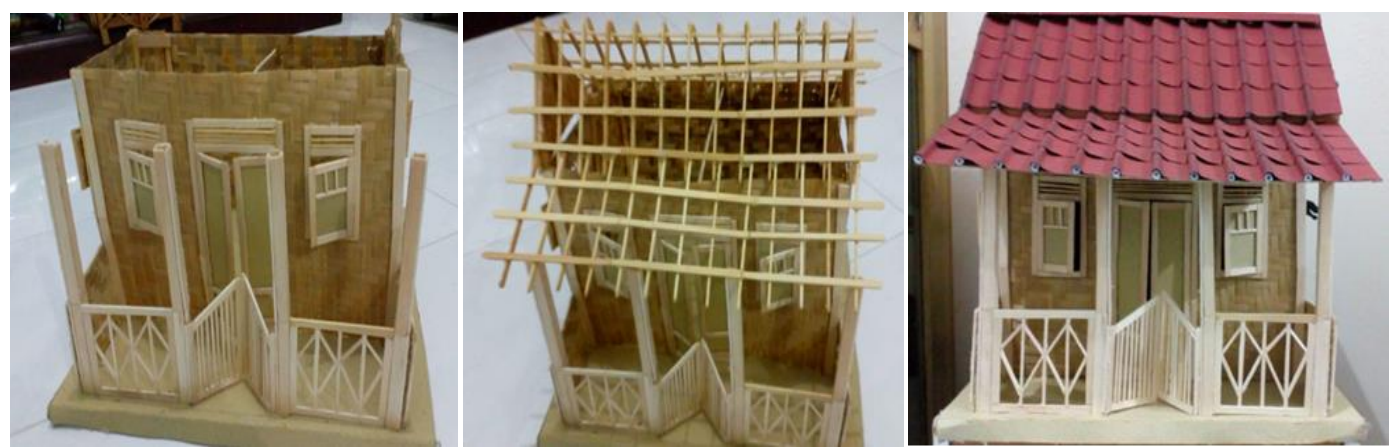

Gambar 12. Media Hasil Pengembangan

Pengembangan media dilakukan dengan memodifikasi bentuk pagar dan dinding sehingga memunculkan konsep-konsep segiempat (persegi, persegipanjang, jajargenjang, layang-layang) dan segitiga. Sedangkan kesebangunan dan kekongruenan terdapat pada kayu reng dan genting rumah.

Media hasil pengembangan tersebut belum melalui tahap validasi dan ujicoba penggunaan dalam pembelajaran sehingga belum dapat ditentukan efektivitasnya dalam pembelajaran.

\section{KESIMPULAN DAN SARAN}

Bentuk dasar rumah Using dapat dikenali melalui bentuk atapnya yang terdiri dari 3 jenis, yaitu cerocogan, baresan, dan tikel balung. Secara umum rumah adat Using dibagi menjadi tiga ruangan yaitu mbyale, jerumah, dan pawon dengan penggunaan komponen-komponen kayu dan bahanbahan alami. Bentuk dasar rumah adat Using dapat digunakan untuk mengenalkan konsep-konsep dasar bidang datar sederhana khususnya bangun segiempat dan segitiga dalam bentuk media pembelajaran matematika. Selain itu adanya perulangan bentuk yang serupa seperti pada genting, dinding, pagar, dan lain-lain juga dapat digunakan sebagai media untuk mengenalkan konsep kesebangunan dan kekongruenan. Penelitian selanjutnya dapat difokuskan pada ujicoba media yang telah dikembangkan berbasis rumah adat Using dalam pembelajaran matematika.

\section{DAFTAR RUJUKAN}

Nur, T. K., Antariksa, \& Sari, N. (2010). Pelestarian Pola Permukiman Masyarakat Using di Desa Kemiren Kabupaten Banyuwangi. Jurnal Tata Kota dan Daerah, Vol. 2, No. 1 , 5973.

Senjaya, L., \& Gunawan, R. (2014). Fasilitas Budaya Osing di Desa Kemiren Banyuwangi. Jurnal eDimensi Arsitektur, Vol II, No. 1 , 343-350.

Setyabudi, I. (2011). Nilai Guna Ruang Rumah Tinggal Suku Using Banyuwangi dalam Kegiatan Sosial, Budaya, dan Agama. Local WisdomJurnal Ilmiah Online, ISSN: 2086$3764,01-08$.

Suprijanto, I. (2002). Rumah Tradisional Osing: Konsep Ruang dan Bentuk. Dimensi Teknik Arsitektur, Vol. 30, No. $1,10-20$.

Yuliatik, E., \& Puji, S. (2014). Suku Osing. Surakarta: Jurusan Seni Media Rekam Institut Seni Indonesia (ISI) Surakarta.

Zhang, W., \& Zhang, Q. (2010). Ethnomathematics and Its Integration within the Mathematics Curriculum. Journal of Mathematics Education, Vol. 3, No. 1 , 151157. 